\title{
Pharmacologic analysis of the mechanism of dark neuron production in cerebral cortex
}

\author{
Zaafir S. Kherani • Roland N. Auer
}

Received: 4 December 2007 / Revised: 29 April 2008 / Accepted: 1 May 2008 / Published online: 3 June 2008

(C) The Author(s) 2008

\begin{abstract}
Dark neurons have plagued the interpretation of brain tissue sections, experimentally and clinically. Seen only when perturbed but living tissue is fixed in aldehydes, their mechanism of production is unknown. Since dark neurons are seen in cortical biopsies, experimental ischemia, hypoglycemia, and epilepsy, we surmised that glutamate release and neuronal transmembrane ion fluxes could be the perturbation leading to dark neuron formation while the fixation process is underway. Accordingly, we excised biopsies of rat cortex to simulate neurosurgical production of dark neurons. To ascertain the role of glutamate, blockade of $N$-methyl-D-aspartate (NMDA) and non-NMDA receptors was done prior to formaldehyde fixation. To assess the role of transmembrane sodium ion (and implicitly, water) fluxes, tetraethylammonium (TEA) was used. Blockade of NMDA receptors with MK-801 and nonNMDA receptors with the quinoxalinediones (CNQX and NBQX) abolished dark neuron formation. More delayed exposure of the tissue to the antagonist, CNQX, by admixing it with the fixative directly, allowed for some production of dark neurons. Aminophosphonoheptanoate (APH), perhaps due to its polarity, and TEA, did not prevent dark neurons, which were abundant in control formaldehyde fixed material unexposed to either receptor or ion channel
\end{abstract}

\section{Z. S. Kherani}

Department of Mechanical and Aerospace Engineering, Princeton University, Princeton, NJ 08544, USA

e-mail: zkherani@princeton.edu

R. N. Auer ( $\square)$

Departments of Pathology and Laboratory Medicine, University of Calgary, 3330 Hospital Dr. NW, Calgary, $\mathrm{AB}$, Canada, T2N 4N1

e-mail: rauer@ucalgary.ca antagonists. The results demonstrate a role for the pharmacologic subtypes of glutamate receptors in the pathogenetic mechanism of dark neuron formation. Our results are consistent with the appearance of dark neurons in biopsy where the cerebral cortex has been undercut, and rendered locally ischemic and hypoglycemic, as well as in epilepsy, hypoglycemia, and ischemia, all of which lead to glutamate release. Rather than a pressure-derived mechanical origin, we suggest that depolarization, glutamate release or receptor activation are more likely mechanisms of dark neuron production.

Keywords Dark neuron · Biopsy artifact · Histology · Excitatory amino acid receptor blocker · Pharmacology · NMDA receptor $\cdot$ APH $\cdot$ MK-801 $\cdot$ CNQX $\cdot$ NBQX $\cdot$ TEA

\section{Introduction}

For almost a century, dark neurons have plagued the interpretation of brain sections in both experimental and clinical material [3]. Dark neurons were first noticed to occur in neurosurgical biopsies, but were not seen at autopsy. Because of their appearance after delayed fixation or after mechanical trauma [23] to the brain prior to fixation, a mechanical stress force [3] was hypothesized to produce dark neurons [4]. This explanation may appear cogent, since it is in accord with the appearance of dark neurons in neurosurgically obtained brain tissue, where biopsies are always subjected to mechanical forces prior to fixation.

However, dark neurons also appear under conditions where no trauma or mechanical forces are applied to the brain. For example, inhibition of the $\mathrm{Na}^{+}-\mathrm{K}^{+}$ATPase pump with ouabain causes dark neurons [6]. Also, epilepsy produces widespread dark neurons throughout the brain, even 
under conditions of excellent fixation [29]. Hypoglycemia gives rise to dark neurons acutely, which can go on to recover over several hours, indicating the reversibility of dark neuron formation. Lastly, ischemia acutely gives rise to dark neurons $[7,17,19]$.

All these conditions either run down neuronal ion gradients (ouabain), release excessive neurotransmitter (epilepsy), release excitatory aspartate (hypoglycemia), or release glutamate (ischemia). Hence, we hypothesized a pharmacologic, and not a pressure-derived mechanical origin of dark neurons. We chose receptor antagonists for the various types of glutamate receptor subtypes [5] to study the role of these receptors in the production of dark neurons, and blocked $\mathrm{Na}^{+}$channels to study the role of sodium and accompanying passive water movement across the cell membrane in the genesis of dark neurons. The results suggest that dark neurons can be prevented using various pharmacologic forms of glutamate antagonism.

\section{Materials and methods}

Male Wistar rats $(n=42)$ weighing $250-300 \mathrm{~g}$ were anesthetized with $2 \%$ halothane administered by a nose cone, which allowed spontaneous ventilation. A scalp incision was made and the skull was exposed. A dental drill was used to excise a circular portion of skull, thereby exposing the cortex. To simulate a neurosurgical cortical biopsy, $2 \times 1 \times 1 \mathrm{~mm}\left(2 \mathrm{~mm}^{3}\right)$ portions of tissue were excised ( $n=126$, three per rat) with a scalpel. These tissue biopsies were then either treated with various antagonists or were left untreated prior to aldehyde fixation.

The biopsies were randomly divided into seven groups. Six of the seven aliquots of cortex were exposed to the pharmacologic antagonists for $3 \mathrm{~h}$ prior to fixation, with two of these groups also undergoing concurrent fixation with antagonist and formaldehyde. The seventh was fixed in formaldehyde, without antagonism, as a positive control for the production of dark neurons. To determine the potential of glutamate receptor blockade and sodium channel blockade in preventing dark neurons, the six treated groups were exposed to the various antagonists. The seventh aliquot of cortical tissue was immersed in $4 \%$ formaldehyde fixative. All antagonists and the fixative were phosphatebuffered ( $0.2 \mathrm{M}$ disodium hydrogen phosphate) to $\mathrm{pH} 7.35$, and the tissue was exposed to all antagonists for $3 \mathrm{~h}$, prior to fixation. Experiments were done at room temperature $\left(22^{\circ} \mathrm{C}\right)$.

$\mathrm{N}$-methyl-D-aspartate (NMDA) receptor blockade, nonNMDA receptor blockade, and $\mathrm{Na}^{+}$channel blockade were all explored. The competitive NMDA antagonist, amino-phosphonoheptanoic acid (APH, $200 \mu \mathrm{M})$ was used because it has been widely studied in the pharmacologic literature. Noncompetitive NMDA antagonism was studied using $15 \mu \mathrm{M}$ MK-801. Non-NMDA antagonism was studied as well, using two 2-amino-3-(3-hydroxy-5-methylisoxazol-4-yl)propionic acid (AMPA) receptor blockers: the relatively hydrophilic 6-cyano-7-nitroquinoxaline-2,3-dione (CNQX) at a concentration of $150 \mu \mathrm{M}$ and the relatively lipophilic 2,3-dihydroxy-6-nitro-7-sulphamoyl-benzo[f]quinoxaline (NBQX) at $150 \mu \mathrm{M}$. In addition, transmembrane $\mathrm{Na}^{+}$channels were blocked with tetraethylammonium chloride (TEA) at $150 \mu \mathrm{M}$.

The cortical tissue was then left overnight in formaldehyde and processed through 40, 70, 95, and 100\% ethanol, followed by xylene and paraffin. Paraffin sections were then cut at a thickness of $6-8 \mu \mathrm{m}$. Sections were finally stained with $\mathrm{H} \& \mathrm{E}$ (a pair/combination of acid and basic dyes), examined, and photographed for the presence of dark neurons.

To determine whether fixation could prevent the salineinduced artifactual swelling, saline and fixative were mixed, and this was used to fix the tissue. The histology was compared to tissue exposed to saline first and then fixed.

We additionally wished to determine the importance of the blockade of receptors prior to fixation. Hence, for one compound, CNQX, we mixed antagonist and fixative, and the resulting mixture was used to fix the tissue. Subsequent examination for dark neurons was carried out against the control tissue that was exposed to CNQX prior to fixation.

Lastly, the ultrastructural appearance of dark neurons was compared to that in previous reports. Tissue was postfixed in $1 \%$ glutaraldeyhde, stained with uranyl acetate and lead citrate, embedded in epon, and examined on a Hitachi M600 electron microscope.

\section{Results}

Phosphate-buffered saline treatment alone yielded marked swelling of neuronal cytoplasm with relative preservation of a shrunken, pyknotic nucleus that was displaced to one side by watery cytoplasm (Fig. 1a). Admixture of saline with formaldehyde (concurrent fixation) yielded no dark neurons (Fig. 1b).

Immersion fixation of excised cortical biopsies yielded abundant dark neurons, with a tendency to occur at the edge of the specimen (Fig. 2), representing either delayed formaldehyde penetration of the center of the biopsy or death of cells in the center of the biopsy over the $3 \mathrm{~h}$ period precluding dark neuron formation.

Tissue exposed prior to fixation to the noncompetitive NMDA antagonist, MK-801, abolished dark neurons. Very few shrunken neuronal forms were visible (Fig. 3).

CNQX pretreatment prevented dark neurons (Fig. 4a), but concurrent fixation using formaldehyde mixed with 


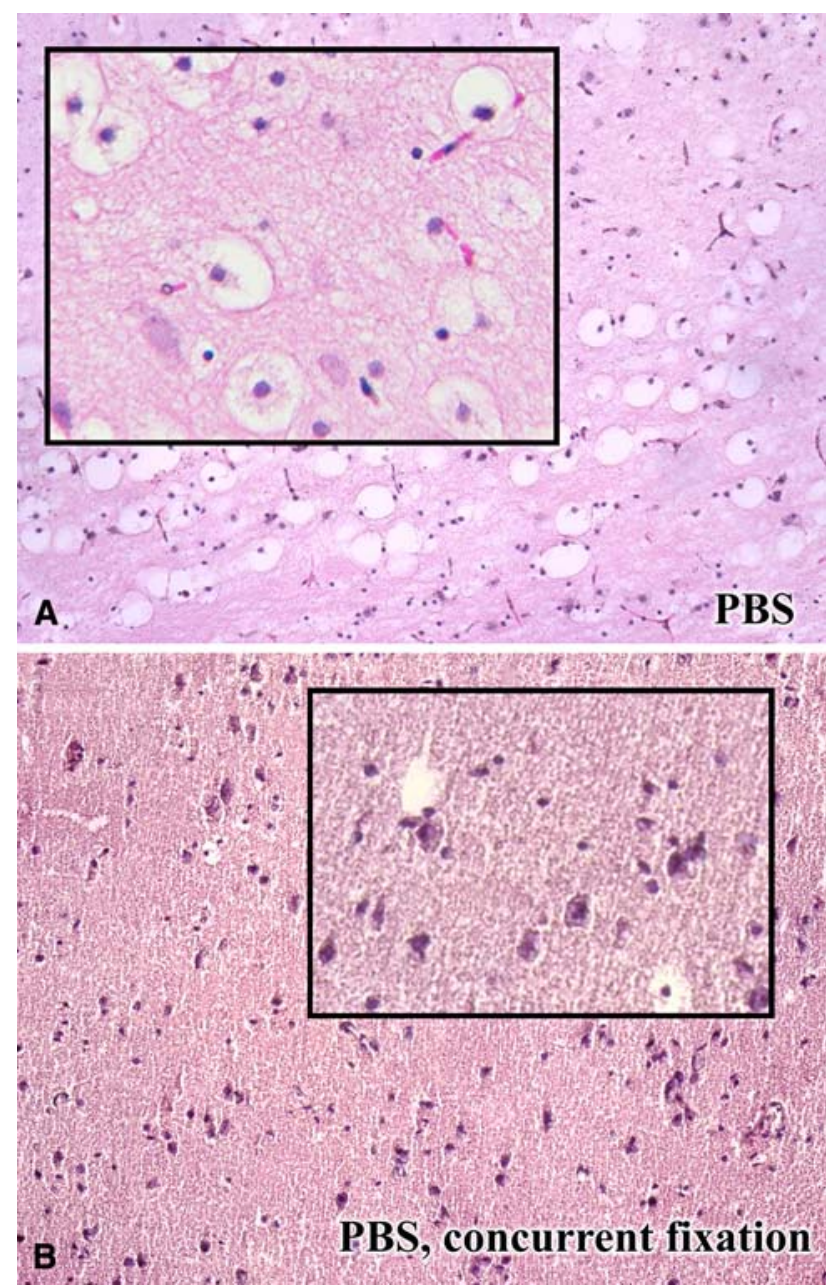

Fig. 1 Effect of phosphate-buffered saline and concurrent formaldehyde fixation with saline. Saline alone led to the well-known watery swelling of cytoplasm (a), while concurrent fixation (b) prevented most of this alteration. Insets show the exploded cells

CNQX prevented some but not all dark neuron formation. Scattered, irregular, small islands of dark neurons could be found (Fig. 4b).

Pretreatment with the competitive NMDA antagonist, $\mathrm{APH}$, did not prevent dark neuron formation in biopsies excised from the cortex (Fig. 5). APH seemed to cause softer tissue than in the other groups, judged by the consistency of the tissue when handled with tweezers.

NBQX pretreatment prevented all dark neuron formation (Fig. 6). Both quinoxalinediones (CNQX and NBQX) led to some degree of hardening of the tissue consistency.

Pretreatment with the $\mathrm{Na}^{+}$channel blocker, TEA, showed no ability to prevent dark neuronal forms (Fig. 7).

Plastic-embedded, toluidine blue-stained sections (Fig. 8) showed the typical dark and light neurons randomly adjacent to each other. Electron microscopy (Fig. 8) showed the preservation of cell membranes, typical of dark neuronal transformation.

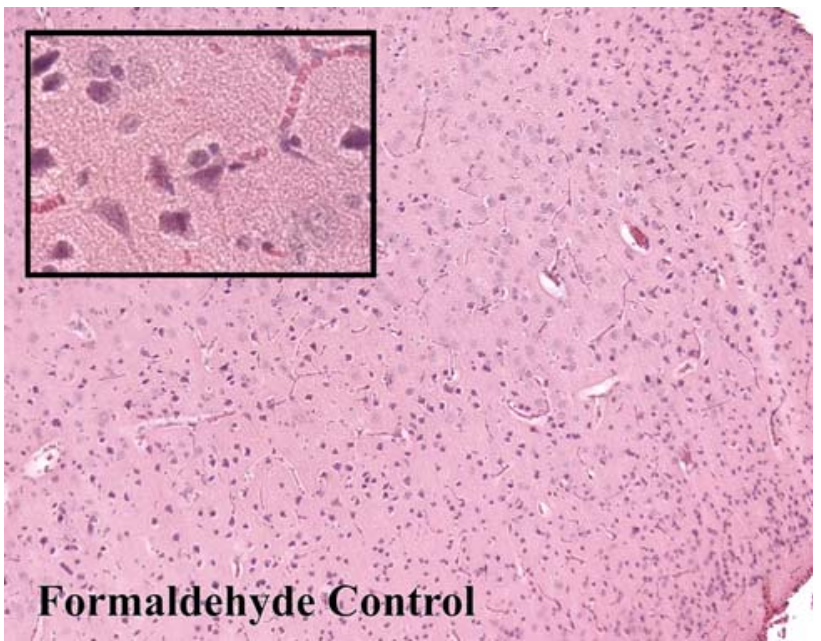

Fig. 2 Direct formaldehyde fixation of excised cortical tissue yielded the well-known "biopsy artifact" with dark neurons seen preferentially around the rim of the specimen, sparing the inner portion (top center). Inset shows that most neurons are dark and contracted, and not always accompanied by corkscrew dendrites

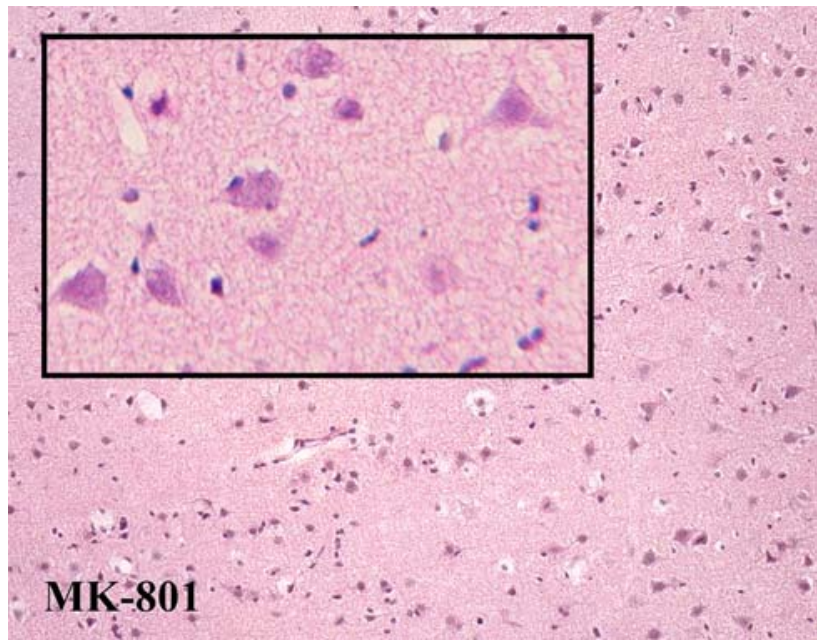

Fig. 3 MK-801 prevented most dark neurons in immersion-fixed tissue sections. Very few dark neurons can be seen at the left, below the inset. Higher magnification (inset) shows no dark alteration, despite the usual fixation-related artifactual spaces surrounding the neurons

\section{Discussion}

Dark neurons occur in clinical and experimental neuropathology where living tissue is fixed with aldehydes, being generally absent from autopsy material unless the postmortem period is short. The formation of dark neurons is thus a biotic reaction that requires living neurons to be fixed. It is not simply due to inadequate fixation [14, 24], since it can be demonstrated when fixation is adequate by in situ microwave irradiation of tissue [21].

Trauma is one of the many methods for experimentally producing dark neurons [23]. Simple trauma was originally 


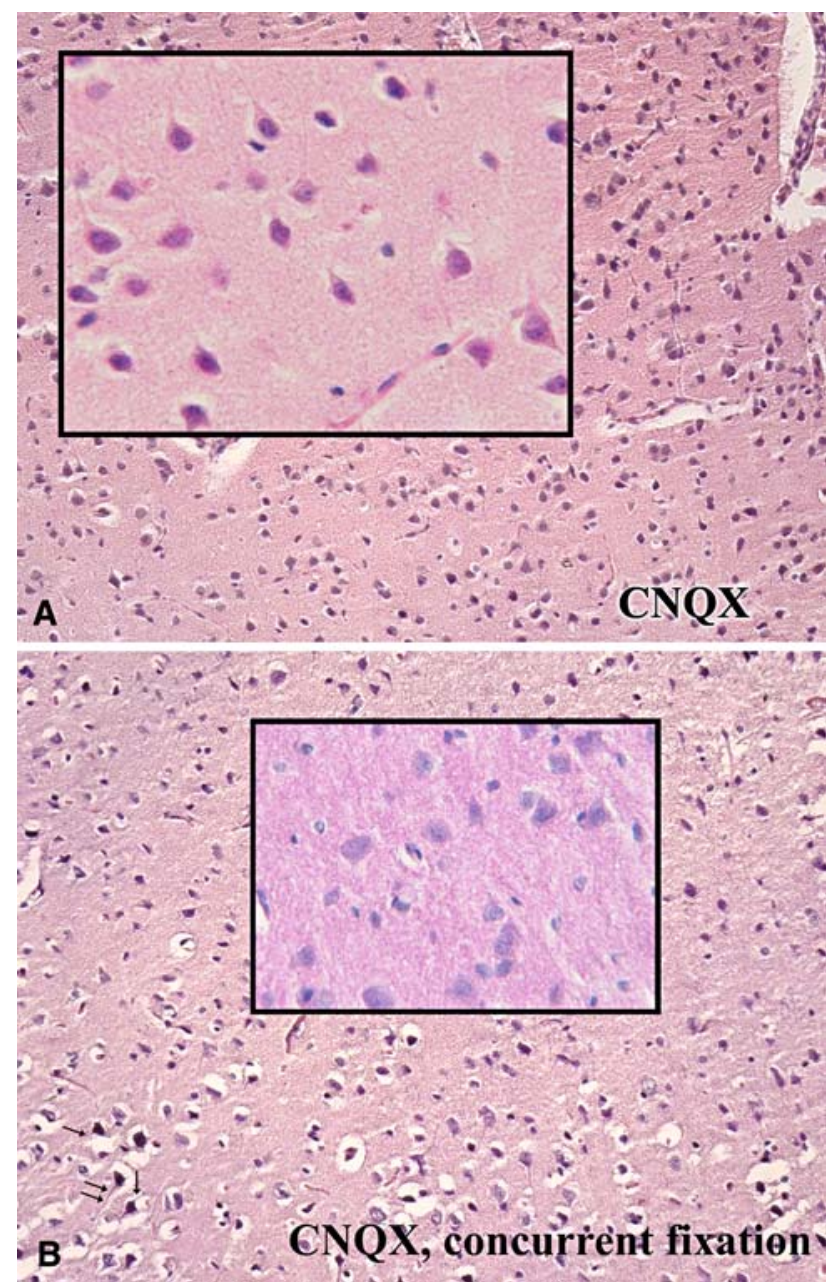

Fig. 4 Effect of CNQX and concurrent formaldehyde fixation with CNQX. Prefixation by CNQX alone prevented dark neuron formation (a), while concurrent fixation (b) abolished some but not all dark neurons. A few are seen here in the lower left, accompanied by the shrunken, corkscrew dendrites (arrows) typical of dark neurons

proposed by Jan Cammermeyer as a physical or mechanical mechanism [3, 4], presumably by causing expulsion of water from the neuron. More modern physical mechanisms have been proposed [11].

However, the occurrence of dark neurons in well-fixed experimental specimens, other than those derived from paradigms of head trauma, indicate that neither trauma nor poor perfusion can account for the occurrence of dark neurons. In perfusion-fixed CNS tissue free of intravascular red blood cells, dark neurons have been shown in ischemia [2, 15, 19], hypoglycemia [1], epilepsy [26, 29], electrical stimulation [13], exposure to excitatory amino acids [27], in addition to mechanical brain trauma. We conclude that neither local nor general brain trauma is a requirement for the production of dark neurons, despite the fact that dark neurons can be produced in mechanical brain injury $[9,12]$.

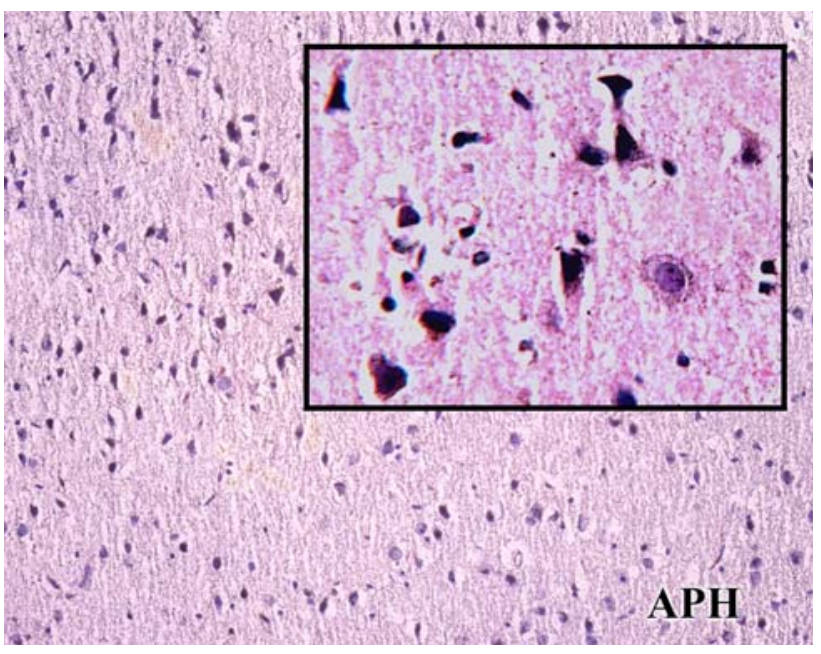

Fig. 5 APH did not prevent the formation of dark neurons, which are shown throughout, and in the inset, where only one non-contracted normal neuronal form is seen

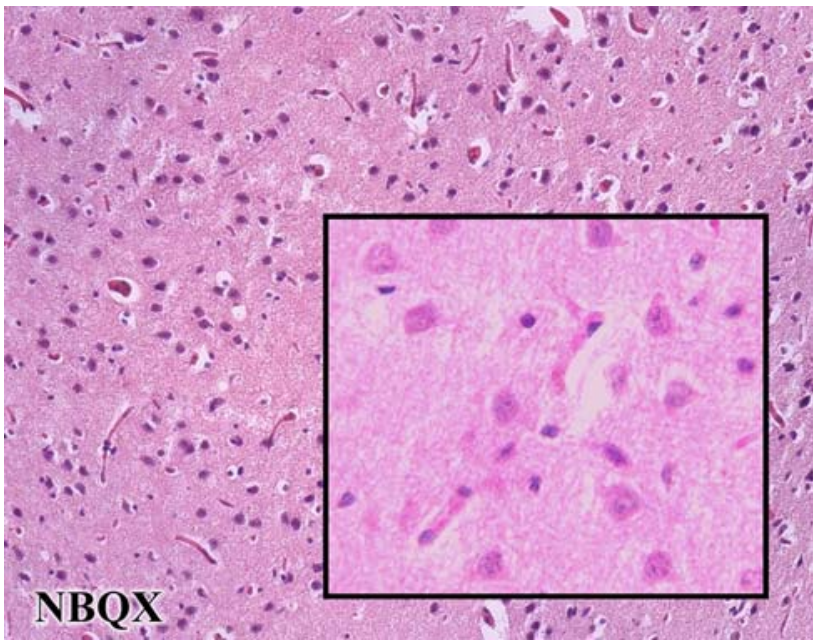

Fig. 6 Pretreatment with NBQX abolished the formation of dark neurons completely. Inset shows the non-contracted neurons

Although spreading depression causes no permanent neuronal injury [22], it does cause gliosis [18], indicating that spreading depression perturbs the tissue. Dark neuron formation might be stimulated by spreading depression. The well-known use of mechanical stimulation to cause both spreading depression and dark neurons might account for the association of mechanical trauma with dark neurons generally in the literature. The phenomenon of spreading depression was discovered in the 1940s by Leão [20] and consists of a wave of depolarization of the cerebral cortex that passes through the cortex in a slow progressive wave of depolarization, followed later by repolarization. The occurrence of spreading depression in cortex may explain not only the presence of dark neurons in cortex, but also their less common occurrence in non-cortical regions of the 


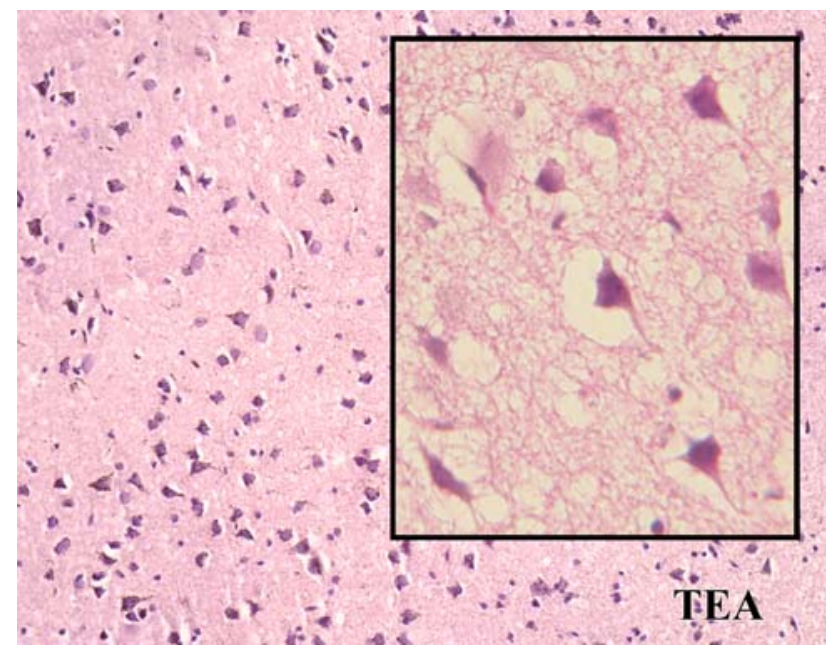

Fig. 7 TEA had no capacity to prevent the formation of dark neurons, which are seen to be present throughout. Higher magnification (inset) shows the typical dendritic accentuation of dark neuron transformation

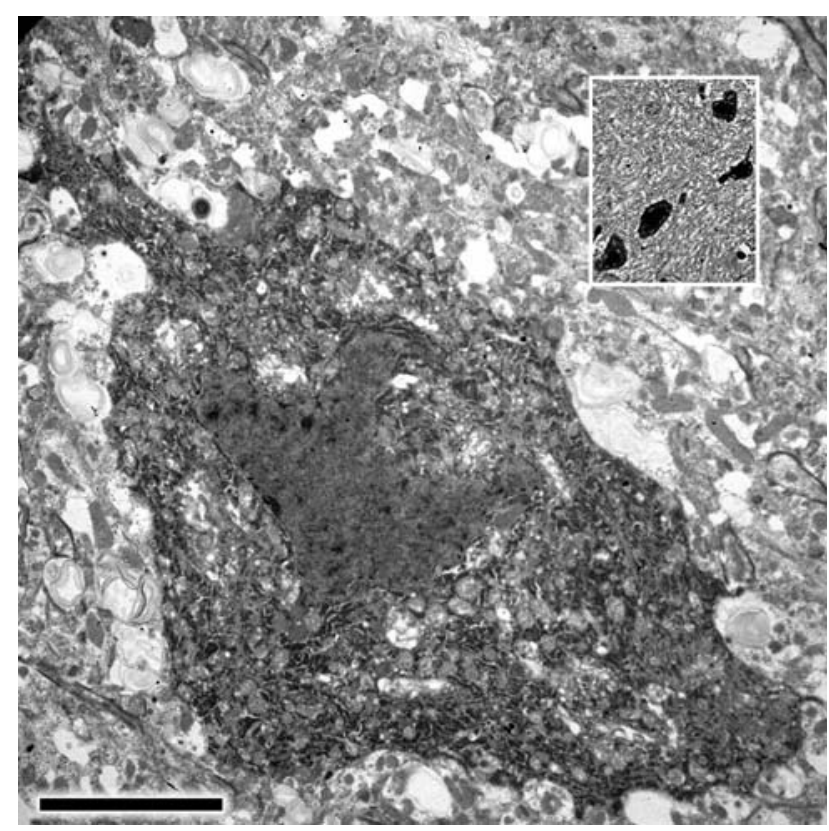

Fig. 8 Toluidine blue-stained, plastic-embedded sections (inset) show typical appearance of homogenously dark nucleus and cytoplasm. Electron microscopy shows the characteristic membrane preservation of a dark neuron, including a process emanating to the upper left, and including the nuclear membrane ( $\operatorname{bar}=5 \mu \mathrm{m})$

brain. A review by Somjen et al. [28] can be consulted for a description of spreading depression.

The requirement for a neuron to be alive but perturbed at the time of fixation explains the well-known absence of dark neurons in autopsy material examined by neuropathologists. The fact that dark neurons are seen in a wide array of experimental conditions [10] underscores their nonspecificity in relation to any one disease process. Conceptually, dark neurons are best considered to be perturbed neurons at the time of fixation.

Infusion of the selective agonist $\mathrm{N}$-methyl-D-aspartate into brain tissue can produce dark neurons [8] and this provided one impetus for our study. Hence, our finding of the prevention of dark neurons by some of the NMDA antagonists tested in the present study might be expected, if dark neurons are indeed caused by depolarization related to tissue glutamate release in injury. Dark neurons were prevented by MK-801, but not the longer, polar molecule $\mathrm{APH}$, perhaps due to its highly polar structure and poor tissue penetration. In contrast, the lipophilic MK-801 molecule easily penetrates the tissue. We did not use slices of tissue, but rather cuboidal blocks, to more closely simulate the neurosurgical biopsy and tissue penetration of antagonist molecules may be a factor in explaining our results.

Although dark neurons have been described as basophilic, they are in fact amphophilic, and show no specific stain affinity, being visible with both acidic and basic stains, as well as silver stains, including Golgi [10]. Physically, they are best considered merely condensed. This might be due to ion and water fluxes caused by neurotransmitter release from cells. A second hypothesis is a role of intracellular actin in the contraction process creating dark neurons. This might be worthy of study, since actin is present in the cell nucleus as well as cytoplasm. A living cell may not be the critical requirement for dark neuron transformation, but merely cellular contractile capability. This could explain their appearance in the early postmortem period, when some biochemical activity is still possible in the tissue, despite somatic death having occurred hours ago. However, the electron microscopic appearance of intact cell and nuclear membranes [1], does suggest that the cell must still be reasonably intact (i.e., with intact cell membranes, and with internal contractile capability intact) to produce this intriguing cellular transformation.

Dark neurons, while appearing intensely black-stained under the electron microscope after uranyl acetate or lead citrate staining and very dark using a panoply of stains under the optical microscope, are still not dead neurons. This common error in interpretation of sections is important, since, for example, steroids may be thought to kill nerve cells if dark neurons are interpreted as dead nerve cells [25]. A recent review has catalogued some of the other instances of misinterpretation of dark neurons as dead neurons [16], underscoring the importance of the nature of dark neurons, and their interpretation in toxicological and other types of experimental neuropathological studies.

The dark neuron may be considered as a neuron at risk of undergoing subsequent cell death, but since recovery and volumetric expansion may occur en masse in dark neurons [1], they are reversibly perturbed cells at the time of fixation. The possible final common pathway causing such 
perturbation is depolarization, and can be due to the release of tissue glutamate or some other excitatory stimulus.

Open Access This article is distributed under the terms of the Creative Commons Attribution Noncommercial License which permits any noncommercial use, distribution, and reproduction in any medium, provided the original author(s) and source are credited.

\section{References}

1. Auer RN, Kalimo H, Olsson Y, Siesjö BK (1985) The temporal evolution of hypoglycemic brain damage. I. Light- and electronmicroscopic findings in the rat cerebral cortex. Acta Neuropathol 67:13-24

2. Brierley JB, Brown AW, Meldrum BS (1971) The nature and time course of the neuronal alterations resulting from oligaemia and hypoglycemia in the brain of Macaca mulatta. Brain Res 25:483499

3. Cammermeyer J (1961) The importance of avoiding "dark" neurons in experimental neuropathology. Acta Neuropathol 1:245270

4. Cammermeyer J (1978) Is the solitary dark neuron a manifestation of postmortem trauma to the brain inadequately fixed by perfusion? Histochemistry 56:97-115

5. Catarzi D, Colotta V, Varano F (2007) Competitive AMPA receptor antagonists. Med Res Rev 27:239-278

6. Cornog JL Jr, Gonatas NK, Feierman JR (1967) Effects of intracerebral injection of ouabain on the fine structure of rat cerebral cortex. Am J Pathol 51:573-590

7. Czurko A, Nishino H (1993) "Collapsed" (argyrophilic, dark) neurons in rat model of transient focal cerebral ischemia. Neurosci Lett 162:71-74

8. Dietrich WD, Halley M, Alonso O, Globus MY, Busto R (1992) Intraventricular infusion of $N$-methyl-D-aspartate. 2. Acute neuronal consequences. Acta Neuropathol 84:630-637

9. Gallyas F, Zoltay G (1992) An immediate light microscopic response of neuronal somata, dendrites and axons to non-contusing concussive head injury in the rat. Acta Neuropathol 83:386-393

10. Gallyas F, Guldner FH, Zoltay G, Wolff J (1990) Golgi-like demonstration of "dark" neurons with an argyrophil III method for experimental neuropathology. Acta Neuropathol 79:620-628

11. Gallyas F, Zoltay G, Dames W (1992) Formation of "dark" (argyrophilic) neurons of various origin proceeds with a common mechanism of biophysical nature (a novel hypothesis). Acta Neuropathol 83:504-509

12. Gallyas F, Zoltay G, Balàs I (1992) An immediate light microscopic response of neuronal somata, dendrites and axons to contusing concussive head injury in the rat. Acta Neuropathol 83:394401

13. Gallyas F, Zoltay G, Horváth Z, Dávid K, Kelényi L (1993) An immediate morphopathologic response of neurons to electroshock; a reliable model for producing "dark" neurons in experimental neuropathology. Neurobiology (Bp) 1:133-146
14. Garman RH (1990) Artifacts in routinely immersion fixed nervous tissue. Toxicol Pathol 18:149-153

15. Jenkins LW, Povlishock JT, Lewelt W, Miller JD, Becker DP (1981) The role of postischemic recirculation in the development of ischemic neuronal injury following complete cerebral ischemia. Acta Neuropathol 55:205-220

16. Jortner BS (2006) The return of the dark neuron. A histological artifact complicating contemporary neurotoxicologic evaluation. Neurotoxicology 27:628-634

17. Kalimo H, Rehncrona S, Söderfeldt H, Olsson Y, Siesjö B (1981) Brain lactic acidosis and ischemic cell damage. 2. Histopathology. J Cereb Blood Flow Metab 1:313-327

18. Kraig RP, Dong LM, Thisted R, Jaeger CB (1991) Spreading depression increases immunohistochemical staining of glial fibrillary acidic protein. J Neurosci 11:2187-2198

19. Kövesdi E, Pál J, Gallyas F (2007) The fate of "dark" neurons produced by transient focal cerebral ischemia in a non-necrotic and non-excitotoxic environment: neurobiological aspects. Brain Res 1147:272-283

20. Leão AAP (1944) Spreading depression of activity in the cerebral cortex. J Neurophysiol 7:359-390

21. Løberg EM, Torvik A (1993) Distinction between artefactually shrunken and truly degenerated 'dark' neurons by in situ fixation with microwave irradiation. Neuropathol Appl Neurobiol 19:359363

22. Nedergaard M, Hansen AJ (1988) Spreading depression is not associated with neuronal injury in the normal brain. Brain Res 449:395-398

23. Ooigawa H, Nawashiro H, Fukui S, Otani N, Osumi A, Toyooka T, Shima K (2006) The fate of Nissl-stained dark neurons following traumatic brain injury in rats: difference between neocortex and hippocampus regarding survival rate. Acta Neuropathol 112:471-481

24. Paljärvi L, Garcia JH, Kalimo H (1979) The efficiency of aldehyde fixation for electron microscopy: stabilization of rat brain tissue to withstand osmotic stress. Histochem J 11:267-276

25. Sapolsky RM, Uno H, Rebert CS, Finch CE (1990) Hippocampal damage associated with prolonged glucocorticoid exposure in primates. J Neurosci 10:2897-2902

26. Sloviter RS (1983) "Epileptic" brain damage in rats induced by sustained electrical stimulation of the perforant path. I. Acute electrophysiological and light microscopic studies. Brain Res Bull 10:675-697

27. Sloviter RS, Dempster DW (1985) "Epileptic" brain damage is replicated qualitatively in the rat hippocampus by central injection of glutamate or aspartate but not by GABA or acetylcholine. Brain Res Bull 15:39-60

28. Somjen GG, Aitken PG, Balestrino M, Herreras O, Kawasaki K (1990) Spreading depression-like depolarization and selective vulnerability of neurons. A brief review. Stroke 21:III179-III183

29. Söderfeldt B, Kalimo H, Olsson Y, Siesjö BK (1983) Bicucullineinduced epileptic brain injury. Transient and persistent cell changes in rat cerebral cortex in the early recovery period. Acta Neuropathol 62:87-95 